Nachgefragt

\title{
Interdisziplinäre Betreuung für vielfältige Probleme
}

Kinder mit Down-Syndrom sind auf eine enge Betreuung angewiesen. Prof. Dr. Tilman Rohrer, Universitätsklinikum des Saarlandes, gibt praktische Tipps für die Behandlung der unterschiedlichen Probleme der Patienten.

? Deutschlandweit gibt es mehrere interdisziplinäre Down-Syndrom-Ambulanzen*. Welche Kinder sollten dort vorgestellt werden?

Professor Tilman Rohrer: Wenn eine Spezialambulanz in der Nähe ist, macht eine orientierende Mitbeurteilung natürlich Sinn, um flankierende Maßnahmen in die Wege zu leiten. Hier können beispielsweise spezielle orthopädische Probleme wie Plattfüße angesprochen werden. Kinder mit Down-Syndrom benötigen gegebenenfalls wegen der Muskelschwäche bereits mit zwei Jahren Einlagen.

? Die Muskelschwäche führt auch zu orofazialen Fehlfunktionen. Welche Folgen hat der offene Mund?

Rohrer: Eine schlaffe Zunge hat zur Folge, dass der Unterkiefer nach vorne kommt, weil der Oberkiefer nicht durch die Zunge auseinandergedrückt wird. Indem die Backenzähne blockieren, kann das Essen nicht mehr zermahlen werden, Brocken werden geschluckt und die Kinder aspirieren. Eine spezielle Physiotherapieform, das Castillo-Morales-Konzept, die bereits im Alter von sechs Wochen beginnen soll, kann die Situation verbessern. Die Übungen zur orofazialen Stimulation durch Vibrationen im Mundbereich müssen mehr-

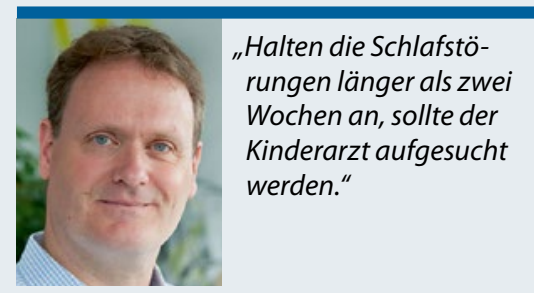

Prof. Dr. med. Tilman Rohrer

Universitätsklinikum des Saarlandes und Medizinische Fakultät der Universität des Saarlandes, Homburg/Saar, Leitlinienkoordinator mals täglich durchgeführt werden. Damit werden Kreuzbiss, Zahnfehlstellungen und kieferorthopädische Probleme vermieden. Wird mit der Physiotherapie ein guter Mundschluss erreicht, können die Kinder trinken und eventuell sogar gestillt werden. Mit der trainierten Muskulatur verbessert sich automatisch auch die Sprache. Nebeneffekte sind besser belüftete Ohren, weniger Mittelohrentzündungen und weitere Verbesserungen der Sprache, weil die Kinder besser hören und deutlicher artikulieren.

? Auf dem Chromosom 21 sind Gene lokalisiert, die für wichtige Enzyme des Aminosäurestoffwechsels kodieren. Welche Folgen hat dies für den Stoffwechsel? Rohrer: Auf dem Chromosom 21 liegen unter anderem mehrere Gene für den Folsäure- und Vitamin-B12-Stoffwechsel Folsäure und B-Vitamine spielen eine wichtige regulatorische Rolle unter anderem im Aminosäurestoffwechsel. Weil Gene durch veränderte Methylierung weniger oder vermehrt deaktiviert und abgeschaltet werden, haben die Kinder einen erhöhten Bedarf an Folsäure. Eine Folge ist unter anderem die frühzeitige Entwicklung von Morbus Alzheimer, das heißt, die Kinder verlernen bereits erreichte kognitive Entwicklungsmeilensteine.

? Können solche Probleme durch eine gezielte Diät oder Supplementierung aufgehalten werden?

Rohrer: Es gibt Versuche, den frühen Morbus Alzheimer zu beeinflussen. Beispielsweise konnte gezeigt werden, dass aktive Folsäure positiven Einfluss hat, aber nur in Kombination mit Schilddrüsenhormonen. Dennoch: Die Studienlage erlaubt bisher nicht den Schluss, dass sich die Stoffwechselsituation durch bestimmte Diäten oder Nahrungsergänzungsmittel verbessern könnte. Wir raten nicht gezielt dazu.
? Ist man den Gründen der Immunschwäche mittlerweile auf der Spur? Rohrer: Im Vergleich mit immungesunden Kindern konnten wir kürzlich quantitative, phänotypische und funktionelle Unterschiede der Effektor-T-Zellen von Kindern mit Down-Syndrom nachweisen. Dies kann zur Erklärung der Immunschwäche beitragen.

? Längst nicht alle DS-Kinder mit Schlafapnoe schnarchen, aber viele sind davon betroffen. Wie kann man sie dennoch sicher erkennen?

Rohrer: $70 \%$ der Kinder mit Down-Syndrom schnarchen manchmal; $21 \%$ fast immer und $60 \%$ sind tagsüber müde. Kennzeichen sind außerdem unruhiger Schlaf, morgendliche Müdigkeit und anstelle des Schnarchens Atempausen von mehr als zehn Sekunden sowie morgendlicher Mundgeruch als Zeichen der Mundatmung, tagsüber Schlafbedarf und Konzentrations- und Lernprobleme.

? Welche Maßnahmen empfehlen Sie gegen die Schlafprobleme?

Rohrer: Relativ konstante Zubettgehzeiten, Fernsehen und Videospiele gehören nicht ins Schlafzimmer, kein helles Licht vor dem Einschlafen, relativ dunkle Schlafzimmer, Verzicht auf koffeinhaltige Getränke sowie Wasch- und Reinigungsmittel, die die Sinne und die Haut zu stark reizen. Halten die Schlafstörungen länger als zwei Wochen an, sollte der Kinderarzt aufgesucht werden. Er soll entscheiden, inwieweit HNO-Arzt, Logopäde, Kieferorthopäde oder Schlaflabor hinzugezogen werden. In den ersten zwei Lebensjahren führen manchmal nur die "Polypen“ zu einer Schlafapnoe und die alleinige Adenotomie kann zur Verbesserung führen. Nach dem vierten Lebensjahr sollte bei gesicherter Schlafapnoe CPAP verordnet werden.

! Vielen Dank für das Gespräch.

Das Interview führte Dr. Christine Starostzik

*www.ds-infocenter.de/downloads/ds_sprechstunde/ DS_Ambulanzen_Uebersicht_Juni2014.pdf 